\section{Action on antibiotics}

Colin Norman reports from Washington on the Food and Drug Administration's (FDA) recent action to ban the use of some antibiotics in animal feeds

After more than a decade of controversy and several years of vacillation, the Food and Drug Administration (FDA) last week took the first formal step towards removing antibiotics from animal feeds, a step long urged by some scientists but bitterly resisted by the agricultural and pharmaceutical industries. The FDA issued a regulation which, provided it survives an expected slew of legal challenges, would prohibit the addition of small amounts of penicillin to premixed feeds for pigs and poultry. A similar negulation banning tetracyclines will follow soon, FDA announced.

Antibiotics have been added to animal feeds in the United States for 25 years, following a discovery that they help promote growth and hence shorten the road to the slaughterhouse. The practice has become so common that, according to figures collected by FDA, some $48.6 \%$ of all antibiotics produced in 1975 were added to animal feeds. In the mid-1960's, however, some scientists began to warn that such widespread use of antibiotics may be contributing to the growing problem of antibiotic resistance among microbes which cause human and animal diseases -resistance which is seriously compromising therapeutic uses of some drugs.

One concern is that bacteria which cause disease in animals will become resistant to antibiotics, thus making the disease more difficult to treat. Another concern is that the resistant bacteria may be transferred from animals to humans either directly or through meat, milk or eggs. An added dimension to the concern is the fact, which is now widely established, that antibiotic resistance can be passed from one strain of bacteria to another-for example, an animal bacterium which becomes resistant to an antibiotic may pass its resistance to a human pathogen through a chance encounter. (Antibiotic resistance is largely determined by socalled R-plasmids, tiny rings of DNA which sit inside a bacterial cell and are reproduced each time the bacterium divides).

Those concerns led the British government in 1968 to establish a special committee, under the chairmanship of Professor Sir Michael Swann, to review the problem. The Swann Committee concluded "the administration of antibiotics to farm livestock, particularly at the sub-therapeutic levels, poses certain hazards to human and animal health", and it recommended a ban on the routine addition to animal feeds of antibiotics used to treat human and animal diseases. The British government swiftly adopted the recommendation, and other European governments have since followed suit.

Following publication of the Swann Report, FDA established a task force of its own to look into the matter, and in February 1972, the task force recommended that restrictions similar to those adopted in Britain should be imposed in the United States. But the task force put an important proviso on that recommendation: the ban should be delayed for up to two years to allow the drug industry time to try to prove its claim that the use of antibiotics in animal feeds does not lead to human health hazards. The deadline slipped by, but FDA took no formal action and non-therapeutic drug use on the farm has continued to increase. According to FDA estimates, 1.2 million pounds of antibiotics were added to animal feeds in 1960, 7.3 million pounds in 1970, and an average of 7.7 million pounds each year between 1971-75.

The first public indication that FDA hadn't completely forgotten about the problem came last April when Donald Kennedy, the new FDA commissioner, announced that FDA was finally prepared to act. "Although we can point to no specific instance in which human disease is more difficult to treat because drug resistance has arisen from an animal source, it is likely that such problems have gone unnoticed", Kennedy said. "The benefit of using these drugs routinely as over the counter products to help animals grow faster or in prophylactic programs does not outweigh the potential risk posed to people", he added. Consequently, Kennedy announced that FDA would seek to eliminate use of penicillin and severely restrict use of tetracyclines in animal feeds. (It should be noted that some antibiotics most critically needed for therapeutic use in man and animals, such as chloramphenicol, semi-synthetic penicillin, gentamycin, and kanamycin, have never been allowed in animal feeds.)

Last week FDA formally published a regulation barring use of penicillin in animal feeds, (it is used chiefly for pigs and poultry), and a similar ban

\section{Sorry, for copyright reasons some images on this page may not be available online}

\section{Donald Kennedy : new commissioner}

on tetracyalines is expected in the next few weeks. Other antibiotics are under consideration, but FDA officials say they do not expect to take action on them in the near future.

The FDA decision is sure to be controversial, and the agriculiture and pharmaceutical industries are expected to challenge it in court. One reason is the economic impact. FDA reckons that eliminating penicillin alone will cost some $\$ 12$ million in lost sales and increase feed costs: the impact of eliminating tetracyclines is expected to be even higher.

The industry is expected to argue on several different grounds. First, there is no demonstrated case in which antibiotic resistance derived from lacing animal feeds has led to untreatable bacterial infection in humans. Second, that resistance to penicillin and tetracyclines is already so widespread that banning their use in animal feeds will make little difference. And third, the chief reason why antibiotic resistance has become such a serious medical problem is that antibiotics have been overused and inappropriately prescribed by the medical profession.

The industry has a right to appeal the FDA decision by filing a complaint and requesting a public hearing, a process which could take up to a year and use of the drugs in animal feeds would be permitted until the appeal is exhausted. After that, the industry could go to court in an attempt to overturn the ban.

Even if the FDA action is ultimately upheld, the use of antibiotics in animal feeds will not be ruled out entirely. The pharmaceutical industry has produced a number of antibiotics which are not used to treat human disease and which may therefore be safer replacements for penicillin and tetracyclines. According to FDA officials, those antibiotics are not in widespread use because they are more expensive than penicillin and tetracyclines. 